\title{
Needs of the families of people with schizophrenia
}

\author{
Julian Leff
}

\section{Origins of family work}

Family therapy for schizophrenia began in the early 1950s, inspired by theories that located the cause of the illness in family dysfunction. The family pathology was seen as stemming from disturbed relationships (Fromm-Reichmann, 1948; Lidz et al, 1956; Laing \& Esterson, 1964) and/or distorted communication (Batesonet al, 1956; Wynne \& Singer, 1963).

Over the next two decades, this approach to treating the dysfunctional 'schizophrenogenic' family gradually fell out of favour for a number of reasons. First, the family treatments were not conspicuously successful (Rubinstein, 1974). Second, there was a dramatic swing in the USA away from psychodynamic theories about the cause of schizophrenia and towards biological explanations. A third factor was the rise of national organisations for relatives of people with schizophrenia, who firmly rejected their implication in the causation of the illness. Despite lack of confirmatory evidence (Hirsch \& Leff, 1975), there was a pervasive climate among psychiatric professionals of blaming relatives, and consequently ostracising them. Relatives were naturally deeply hurt, baffled and resentful of this exclusion by their loved one's professional carers. Although professional attitudes have moderated over the years, there are still persisting beliefs that relatives are to blame for the appearance of schizophrenia in a family member. Even in the absence of overt blame, relatives' requests for information about the patient's condition are often denied on the grounds of confidentiality. It is within this context that we have to consider the needs and wants of the families of people with schizophrenia.

\section{Expressed emotion}

Over the past two decades a number of research teams have developed methods of working with the families of people with schizophrenia, which have been evaluated in controlled trials and found to be efficacious. The impetus to this development was the research on expressed emotion (EE) (Leff \& Vaughn, 1985), which is a measure of one person's emotional response to another person who is suffering from an illness. This phrasing is deliberately general, because research on EE has extended in two directions beyond the original focus on relatives of people with schizophrenia (Brownet al, 1972). Many other conditions have now been studied, including a broad range of psychiatric

\footnotetext{
Box 1. Relatives with high expressed emotion attitudes have been found in

Psychiatric conditions Physicalconditions

Schizophrenia Epilepsy

Manic-depressive Parkinson's disease

psychosis

Depressive neurosis infarction

Learning difficulties Diabetes

Dementia Ulcerative colitis

Post-traumatic stress Crohn's disease

disorder

Child abuse

Hyperactive children

Eating disorders

... and in normal couples
} 
illnesses and a number of physical diseases. High$\mathrm{EE}$ attitudes have been identified in the relatives of people with various conditions (Box 1), as well as in $8 \%$ of normal couples.

The other extension of the research has been to professional carers. A series of studies in the past few years has established that care staff in sheltered accommodation can develop critical and hostile attitudes to the residents. The proportion of highEE relationships in studies of care staff varies from 13 to $62 \%$ (Willetts \& Leff, 1997).

These findings demonstrate that high-EE attitudes cannot be a specific cause of schizophrenia since they occur in a wide range of psychiatric and nonpsychiatric conditions, and are exhibited by professionals who are unrelated to the patients. These studies and a review of the relevant research literature (Hirsch \& Leff, 1975) justify giving reassurance to relatives that they are not responsible for the appearance of schizophrenia in a family member.

\section{Expressed emotion and outcome of schizophrenia}

A link between EE and relapse of schizophrenia has been firmly established by numerous studies conducted in a variety of countries, cultures and languages. Critical comments, hostility and overinvolvement are associated with an increased relapse rate, while a high level of warmth is linked with a good outcome. Thus, it appears that relatives can influence the outcome of schizophrenia either in a negative or in a positive direction. On average, about half the patients living in a high-EE home relapse in the course of nine months compared with about $20 \%$ of those in a low-EE home (Bebbington \& Kuipers, 1994).

Two factors have been identified as protecting patients in high-EE homes. Maintenance antipsychotic drugs reduce the relapse rate by about half, and a similar degree of protection against relapse is conferred on patients who spend little time in the company of their high-EE relatives. If both protective factors are operating, there is an additive effect and the relapse rate is very low indeed (see Table 1).

\section{Development and evaluation of family interventions}

These results present an obvious opportunity for interventions which would have the aims of

\begin{tabular}{|c|c|}
\hline Context & $\begin{array}{c}\text { Relapse rates } \\
\text { over nine months }\end{array}$ \\
\hline $\begin{array}{l}\text { High social contact, } \\
\text { no medication }\end{array}$ & $92 \%$ \\
\hline $\begin{array}{l}\text { High social contact, } \\
\text { medication }\end{array}$ & $53 \%$ \\
\hline $\begin{array}{l}\text { Low social contact, } \\
\text { no medication }\end{array}$ & $42 \%$ \\
\hline $\begin{array}{l}\text { Low social contact, } \\
\text { medication }\end{array}$ & $15 \%$ \\
\hline
\end{tabular}

stabilising patients in high-EE homes on maintenance medication and then attempting to reduce social contact between relatives and patients and/or lower EE. Our own team was spurred by these findings to develop an intervention programme with these specific aims (Kuipers et al, 1992). Other groups at about the same time or in subsequent years created programmes with similar aims based on the EE research. At least eight of these programmes have been evaluated by randomised controlled trials. The results have been very consistent: family interventions in combination with maintenance antipsychotic drugs significantly reduce the relapse rate over nine months compared with drugs alone (Leff, 1996). Four of the studies included a two-year followup, over which time the addition of family interventions to medication reduced the relapse rate from about two-thirds to one-third. The evidence from these studies is compelling enough for the Cochrane Collaboration to endorse family interventions in schizophrenia as efficacious (Anderson \& Adams, 1996). Two of the trials included an economic component, which demonstrated that the costs of the intervention were more than offset by the savings in the costs of service use stemming from the lowered relapse rate (Cardin et al, 1985; Xiong et al, 1994).

The success of these research groups in developing efficacious interventions prompts the question of which common elements they share and hence what the standard clinical service should be offering its clients. The similarity in the content of these programmes is obscured by the bewildering diversity of titles they bear: 'behavioural family therapy', 'family psychoeducation' and 'family work' are just a few. Each team has attempted to stake its claim in the field by inventing a new title for what it does. However, the common elements are readily identifiable and can be recommended to the clinician. 


\section{Common elements in family interventions}

\section{Education about schizophrenia}

All the programmes begin with an education package, but the methods of delivery differ. Some centres give the education to individual families in their own homes, whereas others run workshops for groups of families in the service facility. In our experience bringing the education to the family home has a distinct advantage in facilitating the process of engagement. Many relatives have had bad experiences with professionals excluding them from consultation or even blaming them for the illness and are understandably wary of being offered something out of the ordinary. When they realise that a member of the team is going to bring them information and to allow them unlimited time to ask questions, they are usually very grateful and welcome them to their home.

The education programme should contain information about the causes of schizophrenia as far as they are currently known. It is useful to start with an explicit statement that relatives play no part in the causation of the illness. In our programme we state that schizophrenia is a disease of the brain, but one that makes the patient very sensitive to their social environment. In presenting the prognosis, it is helpful to focus on the good outcome for a substantial proportion of patients. The World Health Organization studies have shown that one in four patients recover completely from a first episode and remain well for some years (Jablensky et al, 1992). The symptoms of schizophrenia should be described, with an equal emphasis on positive and negative symptoms. It is important for relatives to understand that negative symptoms are an integral part of the illness since they are more often the target of criticism than positive symptoms. This section should be adapted to the particular symptoms experienced by the patient in question. For example, the therapist might say that hearing voices is

Box 2. Education about schizophrenia

Education should include information on causation, prognosis, symptoms, treatment and management

A brief package produces little change

Education should continue throughout work with the family common in schizophrenia, and go on to remark that John seems to have been hearing voices, and then ask the patient to tell the family how this has affected $\mathrm{him}$. This has the benefit of encouraging the relatives to empathise with John and also helps to demystify the illness.

The value of medication both as a treatment for the symptoms and as a prophylactic measure needs to be stressed. It is essential, however, to explain and describe possible side-effects. The point should be made that even when the patient stops taking the medication, symptoms do not return immediately, and that this does not indicate that the drugs are unnecessary. The family needs some tips about management, particularly the importance of avoiding arguments and of keeping as calm an atmosphere as possible. Care should be taken not to overwhelm them with advice on how to behave, because this has very little impact. People cannot readily control their emotional behaviour in response to admonitions, and it is likely to take months of work with the family to effect the desired changes.

The term psychoeducation has come to stand for family interventions as a whole, but is unfortunately open to misinterpretation. It does not mean that the clinician's duty to the family is discharged by giving factual information in a couple of sessions. A number of studies have shown that education by itself produces very little change. In our own research we found that two sessions of education teaches the family the name of the disease and increases their optimism but does very little else. It must be recognised that information is not emotionally neutral and that family members may need to hear the same message many times before they are able to accept it, assimilate it and use it. For that reason, education continues throughout the period of time the therapist works with the family (see Box 2).

\section{Assessment of family's strengths and weaknesses}

Seeing the family together during the education sessions enables the therapists to make an assessment of their interaction. As much attention needs to be paid to their strengths as to their weaknesses. It is all too easy to focus on the family's problems and to come away with a pervasively negative picture of the family. However, it is a good discipline to list their strengths as a routine exercise in the assessment. A sense of humour, an ability in the past to sustain a heterosexual relationship, a talent for drawing, or simply the fact that the family has stayed together, can all count as strengths. It is these identified strengths that the therapists will need to build on in their work with the family. 


\section{Problem-solving}

The cognitive-behavioural approach to analysing and solving problems is an essential skill for families to learn. Life with a person suffering from schizophrenia is fraught with problems, often occurring on a daily basis. Consequently, when therapists ask the family what their problems are, they are likely to be swamped with a multitude of them. If any useful work is to be done, it is essential to ask the family to choose one problem to work on and to ensure that this problem remains in focus until it is satisfactorily dealt with. A skilful therapist will guide the family towards selecting a problem that is relatively easy to solve, so that they experience success early on and gain in confidence.

First, the chosen problem is examined from each member's perspective, then broken down into manageable steps. For each step, solutions are solicited and a choice made by the family of the one they will try out. Here again the therapist has a role in guiding the family towards choosing a low-EE solution without appearing to be dictatorial. One of the advantages of a relatives' group is that low-EE solutions to problems are usually suggested by one or other of the members, and relatives are more likely to accept suggestions from those struggling with the same problems than from professionals.

It is advisable to formulate a task derived from the problem-solving activity before the end of each session. It is important to obtain the agreement of the family as a whole that they will cooperate in ensuring that the task is attempted. The therapists make it clear that they will ask for feedback on the task at the next session. If the family has not managed to complete the task, they should not be blamed for their failure. Instead the therapists should state that the task they set was too ambitious and that something less demanding needs to be worked out.

\section{Improving communication}

Many families of people with schizophrenia communicate adequately. However, when emotions are running high, family members tend to talk over each other and cease listening to each other. It is particularly difficult for people with schizophrenia to make themselves heard, because their communication skills are often deficient. Communication can be improved by presenting a few simple rules and requesting the family to observe them (Box 3 ).

The purpose of the first rule is obviously to stop people interrupting others and speaking over them. This can be difficult to enforce, particularly if family members are anxious or conflict is rife. Gentle but
Box 3. Rules to improve communication

Only one person may speak at a time

Everyone should have a fair share of the conversation

Only direct communication is allowed

firm reminders need to be given to those who continue to disregard this rule. The 'fair share' rule is established for two reasons: to rein in those who attempt to dominate the conversation, and to make space for the person with schizophrenia to express themself. It is sometimes necessary to give each person a set time to speak in order to ensure fair shares. The third rule attempts to eliminate indirect communication. It is very common for relatives to refer to the person with schizophrenia in the third person, particularly.when making critical remarks. They may say "She never brushes her hair" or "He spends his money on rubbish". The use of the third person represents a failure to acknowledge the presence of the person with schizophrenia and must undermine their sense of reality. Direct communication not only affirms the existence of the other person, it also tones down negative affect. It is much more difficult to say "You're a lazy slob" than "He's a lazy slob".

It is important to promote active listening both for the sake of the family members and because if they fail to listen to each other, they are unlikely to pay attention to what the therapists say. This aim can be achieved by drawing one person's attention to something said by another and asking them to repeat it in their own words.

\section{Lowering expressed emotion}

The approaches to reducing criticism and overinvolvement are necessarily different. Whereas criticism is as common in partners as in parents, overinvolvement is almost confined to parents and is found more frequently in mothers than in fathers. Furthermore, it often seems to have been present for years before the patient's illness became apparent, whereas criticism is usually recent in origin. As a result, it usually takes much longer to have an impact on overinvolvement than on criticism.

\section{Modifying criticism}

The principal aim is to transform the negativity of critical remarks into positive requests for change. The first step is to identify the caring behind the 
criticism. Criticism is an expression of anger, and people do not become angry unless they care. For example, if a relative complains that the patient is always wearing dirty clothes, it shows that the relative really cares about the patient's appearance. An angry remark about the patient looking like a tramp can be rephrased as a request for the patient to take more care with his/her appearance. Instead of complaining "You always look a fright", the relative can be persuaded to say "I would really like you to put on a clean shirt". This request can then become the basis of a task on which the relative and patient work together using a problem-solving approach.

\section{Reducing overinvolvement}

It is important to recognise that an overinvolved relationship is symmetrical: the relative is anxious about and overprotective of the patient, and the patient is anxious about and overprotective of the relative. The overprotective behaviour of the relative increases the loss of skills and lack of confidence produced by schizophrenia, and promotes the patient's dependence on the relative. Conversely the relative's total absorption by the care of the patient renders them dependent on the patient for the fulfilment of their valued role. In order to separate the two partners, it is necessary to reduce the anxieties of both of them about the consequences. Without this work, which can take months or even years to achieve, attempted separations are very likely to be sabotaged by one or both partners. Placing the patient in sheltered accommodation without this preparation often leads to the relative complaining about the food and/or the care staff, and taking the patient back home. Alternatively, the patient may frequently abscond to return home, but the relative fails to inform the staff of the patient's whereabouts.

Anxiety can be tackled by encouraging brief trial separations: the relative is given an errand which will take them out of the home for about half an hour, while the patient is set a task which is likely to increase their confidence, such as hoovering their bedroom. Before attempting this, it is essential to explore both partners' worst fears about what might happen during their brief time apart. The relative needs to find another role which can replace the satisfaction they gain from their caring. It is helpful for the therapists to give the relative permission to relinquish some of their responsibilities by congratulating them on the hard work they have put into caring and telling them that they have earned a rest. Overinvolved relatives often find some relief from their sense of guilt by attending a relatives' group and discovering that others face similar problems.

\section{Resolving conflict}

Patients can respond to criticism by withdrawing or by fighting back. The second form of response leads to conflict, which can readily escalate into violence. Conflict may also erupt between parents caring for a family member, particularly if one is overinvolved (usually the mother) and the other critical (usually the father). The therapists need to stop conflict as soon as it appears, as these families have lost control of their emotional responses. The arguing partners need to be told that they each have something important to say, and that the therapists will hear them one after the other and help them to find common ground. The therapists need to ease themselves out of this controlling role gradually as the family members become increasingly able to manage their own emotional responses.

\section{Coping with loss}

Relatives often experience two types of loss: the loss of their hopes and expectations for their child, if they are parents, and the loss of the person they used to know. This may be intense enough for them to express the feeling that they are living with a stranger. They need to work through their feeling of grief if they are to move on to acceptance, but this is too painful for the patient to be exposed to. The relatives' group is an appropriate setting for this work, as all relatives will have experienced loss of some degree.

\section{Expanding social networks}

Social groups are an important source of emotional and material support for the families of people with schizophrenia. Unfortunately, it often happens that families withdraw from their natural support networks through shame and embarrassment once the illness appears. They need to be encouraged to resume contact with their friends and relatives. Informing them about the illness is one way of dispelling the shame that stems from ignorance, but there is a pronounced stigma attributed to schizophrenia by the public which is hard to ignore or overcome. The relatives' group is an invaluable resource in this respect, as family members feel more comfortable sharing their distressing experiences with others who have faced the same problems. Relatives who meet in the group often strike up a social acquaintance and start meeting informally.

Increasing the patient's social network requires a different strategy, since schizophrenia often erodes social skills. Training in social skills, if available, can be effective. Sometimes a healthy sibling can be 
recruited to introduce the patient to a social circle outside of the family, although they may be reluctant to expose the patient to their friends. Volunteer befrienders should be considered as a possible companion for the patient.

\section{Reducing contact}

A number of the strategies already considered will lead to a reduction in contact between patient and relatives, but additionally one needs to consider offering the patient attendance at a day activity centre if they are unemployed. Adult education classes should also be brought to the attention of patients and relatives. For patients in parental homes, living apart can be a long-term aim, but will be hard to achieve if an overinvolved relationship exists.

\section{Adjusting expectations}

Family members often expect too much of the patient too soon, although occasionally relatives expect too little and tolerate a very low level of functioning. The family needs to be told that after an episode of schizophrenia there is a prolonged convalescent period during which the patient will gradually return to a more normal level of activity and functioning. The patient may also need help in setting goals which are achievable.

\section{Setting up a relatives' group}

The advantages of a relatives' group are apparent from the foregoing, but in addition it is an efficient method of delivering the interventions. Some research teams have offered families sessions in their own homes (Falloonet al, 1982; Leff et al, 1982; Tarrier et al, 1988). There are strong arguments for this: home visits engage most of the families, whereas many relatives fail to come to a group when invited. Furthermore, patients living with relatives who refuse to attend a group have a particularly bad outcome (Leff et al, 1989). However, when an invitation to join a group is preceded by a few sessions in the home, most relatives will attend.

Two therapists can run a group for six to eight families, meeting for an hour and a half once every two weeks, although on average individual relatives attend about once a month. The location and time of the group clearly need to be established according to the relatives' needs. McFarlane et al (1995) argue for the use of multi-family groups, in which the patients are included as well as their relatives. There has been little experience of these in the UK but they may prove to be the most efficient agents of change. Leff et al (1989) found that a relatives' group was better at reducing EE, whereas family sessions had more impact on social contact.

\section{Resource implications}

\section{How many therapists?}

Some research teams have used two therapists for each family, and there are good reasons for this (Kuipers et al, 1992). But this may be beyond the resources of some community teams. However the intervention is delivered, the therapists need support and this is best provided by holding a therapists' support group about once a month. This acts as a think-tank for difficult problems as well as a forum for therapists to unload their emotional responses to the families.

\section{Prioritising}

All families of people with schizophrenia need some professional help and support, but given the lack of appropriately trained personnel, it is usually necessary to prioritise those families in greatest need (Box 4). In the absence of an EE assessment, there are some simple indicators of families which need help the most. On average, patients in low-EE homes relapse once in three years, whereas the relapse frequency in high-EE homes is once per year. Families which cannot control their anger are at high risk for physical injury. The lack of control is often manifested by calling in the police. Relatives who cannot cope with the problems tend to make persistent demands on staff and attempt to draw in a multiplicity of agencies. This activity has the unfortunate effect of antagonising staff so that the family does not receive the help they desperately need.

\section{Who should give the intervention?}

Any psychiatric professional can be trained in the skills of family work, but the most obvious candidate is the community psychiatric nurse (CPN). Over five years ago a national training programme was established in Manchester and London with the aid of a grant from the Thorn Charitable Foundation (see Appendix). More than $250 \mathrm{CPNs}$ have now been trained on this course and evaluation of the trainees has shown that they acquire the appropriate 
Box 4. Families in most need

Patients living with relatives, who take their medication but relapse more than once a year

Families in which arguments erupt into violence

Families which call in the police

Relatives who constantly make demands on the staff

knowledge and attitudes to the work (Leff \& Gamble, 1995). Satellite training centres are now being set up with the aim of making the training accessible to staff nationally.

\section{What do the families of people with schizophrenia need?}

A survey by the National Schizophrenia Fellowship revealed that relatives wanted information about the illness and improved coping skills. The training now becoming available to psychiatric professionals should satisfy this need. However, what is also required is a change in the attitude of staff. Relatives should be respected for the caring they undertake day and night for years on end. They do not want to be considered pathogenic, and suitable cases for treatment. Instead, they wish to be regarded as partners in the struggle against schizophrenia, and professional carers should respect this wish and respond to it. The problems of living with schizophrenia are so enormous that only cooperation within the family, and between non-professional and professional carers, can overcome them.

\section{Appendix}

\section{National training centres for Thorn courses}

\section{London Thorn Initiative}

Administrator: Sheila Maister

Institute of Psychiatry, De Crespigny Park, London SE5 8AF

\section{Manchester Thorn Initiative}

Administrator: Alison Davies

School of Nursing, Coupland 3 Building, University of Manchester, Oxford Road, Manchester M13 9PL

\section{References}

Anderson, J. \& Adams, C. (1996) Family interventions in schizophrenia. British Medical Journal, 313, 505-506.

Bateson, G., Jackson, D. D., Haley, J., et al (1956) Toward a theory of schizophrenia. Behavioral Science, 1, 251-264.

Bebbington, P. \& Kuipers, L. (1994) The predictive utility of expressed emotion in schizophrenia: an aggregate analysis. Psychological Medicine, 24, 707-718.

Brown, G. W., Birley, J. L. T. \& Wing, J. K. (1972) Influence of family life on the course of schizophrenic disorders: a replication. British Journal of Psychiatry, 121, 241-258.

Cardin, V. A., McGill, C. W. \& Falloon, I. R. H. (1985) An economic analysis: costs, benefits, and effectiveness. In Family Management of Schizophrenia (ed. I. R. H. Falloon), pp. 115-124. Baltimore, MD: Johns Hopkins University Press.

Falloon, I. R. H., Boyd, J. L., McGill, C. W., et al (1982) Family management in the prevention of exacerbations of schizophrenia: A controlled study. New England Journal of Medicine, 306, 1437-1440.

Fromm-Reichmann, F. (1948) Notes on the development of treatment of schizophrenics by psychoanalytic psychotherapy. Psychiatry, 11, 263-273.

Hirsch, S. R. \& Leff, J. P. (1975) Abnormalities in Parents of Schizophrenics (Maudsley Monograph no. 22). London: Oxford University Press.

Jablensky, A., Sartorius, N., Ernberg, G., et al (1992) Schizophrenia: Manifestations, Incidence and Course in Different Cultures. A World Health Organization Ten-Country Study (Psychological Medicine Monograph Supplement no. 20). Cambridge: Cambridge University Press.

Kuipers, L., Leff, J. \& Lam, D. (1992) Family Work for Schizophrenia: A Practical Guide. London: Gaskell.

Laing, R. D. \& Esterson, D. (1964) Sanity, Madness and the Family. London: Tavistock.

Lidz, T., Cornelison, A. R., Fleck, S., et al (1956) The intrafamilial environment of the schizophrenic patient. II: Marital schism and marital skew. American Journal of Psychiatry, 114, 241-248.

Leff, J. (1996) First perceptions of treatment: The physicianfamily-patient network. Journal of Practical Psychiatry and Behavioural Health, 2 (suppl.), 10-15.

- Kuipers, L., Berkowitz, R., et al (1982) A controlled trial of social intervention in the families of schizophrenic patients. British Journal of Psychiatry, 141, 121-134.

— \& Vaughn, C. (1985) Expressed Emotion in Families: Its Significance for Mental Illness. New York: Guilford.

-, Berkowitz, R., Shavit, N., et al (1989) A trial of family therapy v. a relatives group for schizophrenia. British Journal of Psychiatry, 154, 58-66.

- \& Gamble, C. (1995) Training of community psychiatric nurses in family work for schizophrenia. International Journal of Mental Health, 24, 76-88.

McFarlane, W. R., Lukens, E., Link, B., et al (1995) The multiple family group, psychoeducation, and maintenance medication in the treatment of schizophrenia. Archives of General Psychiatry, 52, 679-687.

Rubinstein, D. (1974) Techniques in family psychotherapy of schizophrenia. In Strategic Interventions in Schizophrenia (eds R. Cancro, N. Fox \& L. E. Shapiro), pp. 99-141. New York: Behavioral Publications.

Tarrier, N., Barrowclough, C., Vaughn, C., et al (1988) The community management of schizophrenia. A controlled trial of a behavioural intervention with families to reduce relapse. British Journal of Psychiatry, 153, 532-542.

Vaughn, C. E. \& Leff, J. P. (1976) The influence of family and social factors on the course of psychiatric illness. British Journal of Psychiatry, 129, 125-137.

Willetts, L. E. \& Leff, J. (1997) Expressed emotion and schizophrenia: the efficacy of a staff training programme. Journal of Advanced Nursing, 26, 1125-1133. 
Wynne, L. C. \& Singer, M. T. (1963) Thought disorder and family relations of schizophrenics. Archives of General Psychiatry, 9, 191-206.

Xiong, W., Phillips, M. R., Hu, X., et al (1994) Family-based intervention for schizophrenic patients in China. A randomised controlled trial. British Journal of Psychiatry, 165, 239-247.

\section{Multiple choice questions}

1. The following measures contribute to the high EE index:
a critical comments
b warmth
c overinvolvement
d hostility.

2. High-EE attitudes have been found in:
a manic-depressive illness
b ulcerative colitis
c cancer of the oesophagus
d epilepsy.

3. There is strong evidence that:

a parents contribute to the causation of schizophrenia

b professional care staff develop high-EE attitudes

c giving relatives information about schizophrenia significantly reduces the relapse rate

d family interventions are an effective substitute for antipsychotic medication.
4. Patients in high-EE homes can reduce the likelihood of relapse by:

a spending time with friends outside the home

b participating in domestic activities

c taking drug holidays

$\mathrm{d}$ attendance at a day centre.

5. The advantages of a relatives' group are:

a relatives find it easier to accept advice from each other than from professonals

b relatives most in need will come to the group

c overinvolved relatives experience relief from their sense of guilt

d it provides an opportunity to work through grief.

\begin{tabular}{|c|c|c|c|c|}
\hline \multicolumn{5}{|c|}{ MCQ answers } \\
\hline 1 & 2 & 3 & 4 & 5 \\
\hline a $T$ & a $\mathrm{T}$ & a $F$ & a $\mathrm{T}$ & a $T$ \\
\hline b $\mathbf{F}$ & b $\mathrm{T}$ & b $T$ & b F & b F \\
\hline c $\mathrm{T}$ & c $F$ & c $\mathbf{F}$ & c $\mathrm{F}$ & c $\mathrm{T}$ \\
\hline d $T$ & d $T$ & d F & d $T$ & d $T$ \\
\hline
\end{tabular}

\section{NEW FROM GASKELL}

\section{Acute Psychosis, Schizophrenia and Comorbid Disorders}

Recent Topics from Advances in Psychiatric Treatment, Vol. 1

\section{EDITED BY ALAN LEE}

This new series will bring together popular articles from Advances in Psychiatric Treatment. These have been updated to provide systematic, authoritative, and well-referenced accounts of key clinical topics relating to modern therapeutic practice. While primarily aimed at senior psychiatric trainees, many of the articles will be of interest to other mental health professionals.

Volume 1 covers the management of acutely disturbed in-patients, drug and psychosocial approaches to the treatment of schizophrenia, and the problems of comorbid substance misuse and homelessness. There are chapters on risk and childbirth, psychoses in the elderly, and the special problems of identifying and treating psychiatric disorders in those with learning disability. There is also practical advice on assessing fitness to be interviewed by the police, and on preparing medico-legal reports.

The book will be especially useful in conjunction with the College Seminars titles for those preparing for the College Membership Examinations.

Paperback, September $1998 \quad £ 15.00,152$ pp., ISBN 1901242161

Royal College of Psychiatrists, 17 Belgrave Square, London SW1X 8PG. Tel: 0171-235 2351 ext. 146; Fax: 0171-245 1231; e-mail: booksales@rcpsych.ac.uk; http://www.rcpsych.ac.uk 